\title{
An Optimization of the Analytical Method for Determining the Flexural Toppling Failure Plane
}

\author{
Xin Qu $\mathbb{D i}^{1}$ and Fangfang Diao $\mathbb{D}^{2}$ \\ ${ }^{1}$ School of Civil and Architecture Engineering, Anyang Institute of Technology, Anyang 455000, China \\ ${ }^{2}$ School of Foreign Languages, Anyang Institute of Technology, Anyang 455000, China \\ Correspondence should be addressed to Xin Qu; xqu1987@163.com
}

Received 8 October 2019; Revised 23 December 2019; Accepted 3 January 2020; Published 28 March 2020

Academic Editor: Harry Far

Copyright ( $) 2020$ Xin Qu and Fangfang Diao. This is an open access article distributed under the Creative Commons Attribution License, which permits unrestricted use, distribution, and reproduction in any medium, provided the original work is properly cited.

\begin{abstract}
According to the results of the physical model tests, the failure plane of an anaclinal layered rock slope was a linear-type plane at an angle above the plane normal to the discontinuities, and the failure mode of rock strata was bending tension. However, the shear failure occurred near the slope toe, the effects of the cohesion of the discontinuities on the stability of the slope, and the contribution of tangential force to cross-section axial force were neglected in such studies. Moreover, none of the experts had developed a rigorously theoretical method for determining the angle between the failure plane and the plane normal to the discontinuities. This paper was initiated for the purpose of solving the problems described above. With the cantilever beam model and a step-by-step analytical method, an optimization of the analytical method for determining the flexural toppling failure plane based on the limit equilibrium theory was developed and the corresponding formulations were derived. Based on the present computational framework, comparisons with other studies were carried out by taking a slate slope in South Anhui in China and a rock slope facing the Tehran-Chalus Road near the Amir-Kabir Dam Lake in Iran. Furthermore, the sensitivity analyses of the parameters used in the calculation process of the failure angle of the slate slope in South Anhui in China were performed. The results demonstrated that the failure plane and the safety factor of the stability obtained with the presented method were credible, which verified the proposed method. The dip angle of the slope, the dip angle of the rock stratum, and the friction angle of the discontinuities were the controlling factors for the overall failure of the slate slope in South Anhui in China.
\end{abstract}

\section{Introduction}

Toppling failure, being a kind of typical instability mode for rock slopes, widely exists in domestic and foreign water conservancy, hydropower, highways, and open-pit mine slope engineering. The toppling instability of slopes has caused great harm to people's lives, property safety, and engineering construction [1-4]. However, due to the cognition limitations of the public with regard to anaclinal layered slopes, these slopes had not been able to arouse people's attention until anaclinal layered toppling landslides frequently occurred. Currently, more and more experts are devoting themselves to the study of anaclinal layered toppling slopes. In [5], the authors divided the toppling failures into three groups, i.e., block toppling, flexural toppling and block-flexural toppling (block-flexural toppling can be treated as a recombined form of the above two types). Numerous significant results had been found for block toppling, and relatively complete theoretical analysis methods were developed [6-12], while researchers continued to be preoccupied with flexural toppling [13-22].

The limit equilibrium method is one of the most common and effective approaches in studies of flexural toppling failure. However, before using the limit equilibrium method for mechanical analyses, the position and shape of the failure plane of a slope must be determined. Thus, many experts put forward various methods to study this problem, and they carried out physical model tests to verify their methods. In [16], the authors first proposed a stability analysis method for slopes and underground openings under various loading conditions against the flexural toppling failure, derived by employing the equations of the limit equilibrium and the 
boundary conditions. They verified the method by carrying out base friction tests and found that the failure plane was a linear-type plane, emanating from the toe of the slope and perpendicular to the discontinuities, i.e., the angle between the failure plane and the plane normal to the discontinuities (called the failure angle in this study) was equal to $0^{\circ}$. In $[13,23]$ and [24], the authors improved Aydan and Kawamoto's theory of flexural toppling failure in open excavations through centrifuge tests and found that the failure angle was $10^{\circ}$. By using the principles of compatibility and the equations of equilibrium along with the governing equations of elastic deformation for the beams, the authors of $[25,26]$ derived equations for determining the intercolumn forces in rock masses with the potential for flexural toppling failure. Since this model did not allow for slippage between layers, this method might yield very low safety factors for short layers near the slope toe, which might only be true for small deflections. In [15], the authors carried out a series of model tests on a single column and slopes under dynamic loading and found that the failure angle was in the range of $0^{\circ}$ to $15^{\circ}$. In [22], the authors developed a new UDEC Trigon approach for simulating the flexural toppling failure. The simulated results showed that the inclination of the total failure surface was around $13^{\circ}$ above the plane normal to the discontinuities.

The above theoretical investigations greatly enriched the understanding of the deformation and failure mechanism of such slopes. The significant achievements can be summarized as two viewpoints, i.e., the failure plane of an anaclinal layered rock slope was a linear-type plane at an angle above the plane normal to the discontinuities, and the failure mode of rock strata was bending tension. However, these studies still have some issues needed to be resolved. For instance, the failure of rock strata was not only the result of bending tension as shear failure often occurred near the slope toe, which was supported by field investigations and theoretical analysis. Furthermore, the effects of the cohesion of the discontinuities on the stability of anaclinal layered rock slopes against flexural toppling failure were neglected, which resulted in underestimation of the stability. In addition, the contribution of tangential force to cross-section axial force was neglected, which caused the calculated tensile stress to be overestimated. Last but not least, the failure angle was obtained only from the laboratory data or numerical simulation results, and none of the experts had developed a rigorously theoretical method for determining the failure angle.

In order to solve the above problems, an optimization of the analytical method for determining the flexural toppling failure plane based on the limit equilibrium theory [27-29] was developed in this study. The basal failure plane was considered as a plane at which the stress of the slope arrived at the state of limit equilibrium, i.e., the plane, at which the residual sliding force at the toe of the slope was equal to zero, was the basal failure plane. With a cantilever beam model and a step-by-step analytical method, the corresponding formulations were derived in this study. Furthermore, the controlling factors for the overall failure of an anaclinal layered rock slope were obtained after the sensitivity analyses of the parameters used in the calculation process of the slope failure angle were performed.

\section{Geological Geometrical Model of an Anaclinal Layered Slope}

The geological geometrical model of an anaclinal layered slope is shown in Figure 1, where $H$ is the slope height, $\beta$ is the dip angle of the slope, $\eta$ is the dip angle of the rock strata, $\eta_{0}$ is the natural slope angle, $\alpha$ is the dip angle of the plane normal to the discontinuities, $\theta$ is the dip angle of the failure plane, $\theta_{r}$ (called failure angle) is the angle between the basal failure plane and the plane normal to the discontinuities, $\beta_{0}$ is the difference between $\beta$ and $\alpha, b$ is the rock thickness, and $h_{i}$ is the contact height between stratum $i$ and stratum $i+1$. According to the geometrical conditions, equation (1) can be obtained as follows:

$$
\left\{\begin{array}{l}
\alpha=\frac{\pi}{2}-\eta, \\
\beta_{0}=\beta-\alpha, \\
\theta=\alpha+\theta_{r} .
\end{array}\right.
$$

\section{Searching Failure Plane}

3.1. Searching Principle. According to the results of the physical model tests $[13,15,16,22-26]$, the failure plane of the failed strata was a linear-type plane at an angle above the plane normal to the discontinuities. However, none of the experts had developed a rigorously theoretical method for determining the failure angle. In this study, the basal failure plane was considered as a plane at which the stress of the slope arrived at the state of limit equilibrium, i.e., the plane, at which the residual sliding force at the toe of the slope was equal to zero, was the basal failure plane.

Due to the limitation of the computer's accuracy, it was unable to guarantee the existence of the failure angle that made the residual sliding force at the toe of the slope equal to zero. An attempt was made to control the error of the failure angle to be in an acceptable range by taking a small size of searching step, and thus, the residual sliding force at the toe of the slope was close enough to zero. The searching direction is shown in Figure 2.

Obviously, the above problem was actually an optimization problem with the failure angle $\theta_{r}$ as a variable parameter, which can be written as follows:

$$
\begin{aligned}
F & =\min \left|f_{j}\left(\theta_{r}\right)\right| \\
f_{j}\left(\theta_{r}\right) & =\max \left(P_{0}, T_{0}\right)
\end{aligned}
$$

Here, $P_{0}$, calculated by the shear failure mode, is the residual sliding force at the toe of the slope, $T_{0}$, calculated by the tension failure mode, is the residual sliding force at the toe of the slope, $\beta_{0}$ is the difference between the dip angle of the slope and the plane normal to the discontinuities, and $n n$ 


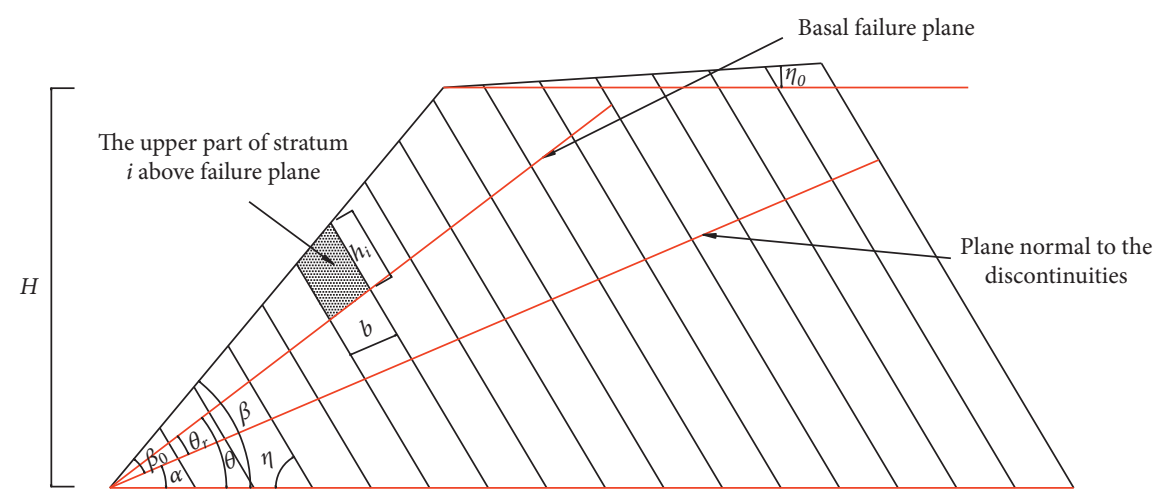

Figure 1: Geological geometrical model of an anaclinal layered slope.

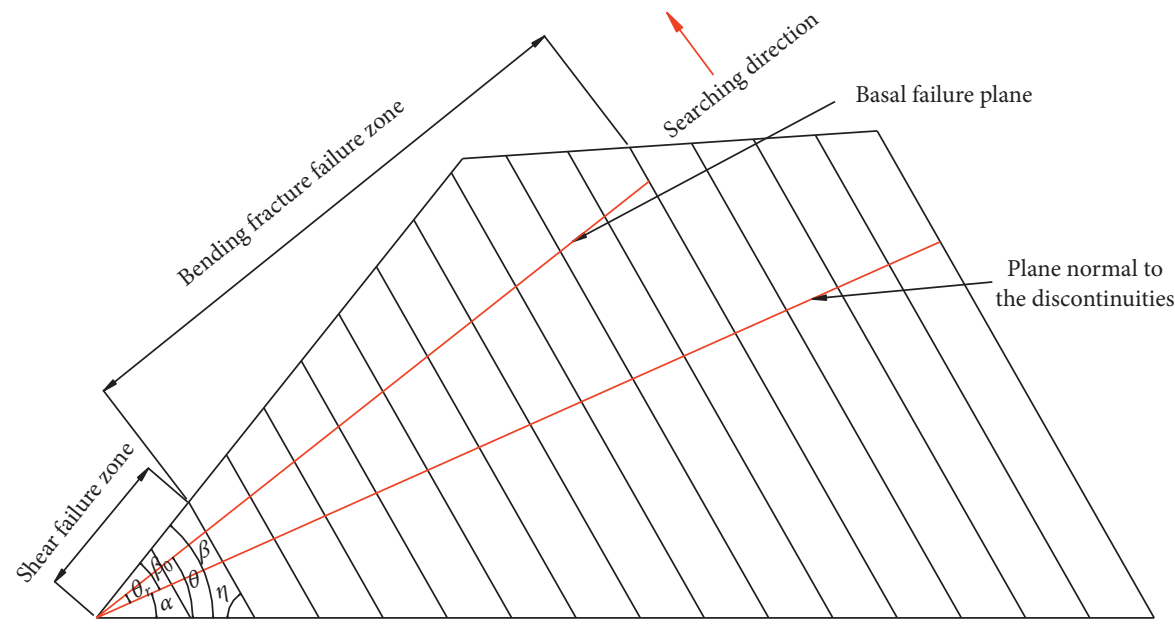

Figure 2: Searching process.

is the searching times. Taking $10^{6}$ as the value of the searching times, the error of failure angle is less than $10^{-4}$, which is in an acceptable range.

$$
\begin{aligned}
\Delta \theta_{r} & =\frac{\beta_{0}}{n n} \\
\theta_{r} & =(j-1) \Delta \theta_{r} .
\end{aligned}
$$

Here, $\Delta \theta_{r}$ is the size of the searching step. According to the geometrical conditions, the contact height $h_{i}$ between stratum $i$ and stratum $i+1$ can be written as follows:

$$
h_{i}=\left\{\begin{array}{l}
i b\left(\tan \beta_{0}-\tan \theta_{r}\right), \quad 1 \leq i<n_{-} t p, \\
{\left[i b\left(\tan \beta_{0}-\tan \theta_{r}\right)-\left(i b-\left(\frac{H}{\sin \beta}\right) \cos \beta_{0}\right)\right.} \\
\left.\left(\tan \beta_{0}+\cot \beta_{1}\right)\right], \quad i \geq n_{-} t p .
\end{array}\right.
$$

$$
\beta_{1}=\eta+\theta_{0} .
$$

Here, $n t p$ is the number of the first stratum on the top of the slope (numbered from the toe to the top of a slope).

After $h_{i}$ was obtained through equation (5), the mechanical analyses of rock strata can be performed based on the slope geometry and the limit equilibrium theory [27-29], which are presented in Sections 3.2 and 3.3.

3.2. Failure Modes. Flexural toppling failure is one of the main types of toppling failures in anaclinal layered rock slopes, and its failure mechanism is due to the bending of layers with or without cross joints. For flexural toppling-type anaclinal layered slopes, although bending tension failure occurred in most of the rock strata, bending tension failure was unlikely to occur in several strata with a small slenderness ratio at the toe of the slopes [22,30]. Loaded by selfweight and thrust provided by the upper and underlying strata, the strata with a small slenderness ratio were likely subjected to shear failure according to actual field investigations [31, 32] and theoretical analysis [33, 34]. In this study, the failure modes of the rock strata in flexural toppling-type anaclinal layered slopes were shear failure and bending tension failure. The specific failure modes of the rock strata (tension or shear) depended on the types of stress (tension or shear) that reached their critical state earlier.

3.2.1. Tension Failure. If tension failure occurs in stratum $i$, it should meet the criterion of the maximum tensile stress theory [35], which can be expressed as follows: 


$$
\begin{aligned}
& \sigma_{\max }=\sigma_{t}, \\
& \sigma_{\max }=\frac{M_{i} b}{2 I}-\frac{N_{i}}{b},
\end{aligned}
$$

where $\sigma_{t}$ is the tensile strength of column $i, M_{i}$ is the bending moment exerted on the center of column $i, I$ is the second moment of inertia, and $N_{i}$ is the axial force exerted on column $i$.

As shown in Figure 3, the bending moment exerted on column $i$ can be written as follows:

$$
M_{i}=\frac{\overline{h_{i}}}{2} w_{i} \sin \alpha+T_{i} \chi h_{i}-\frac{1}{2} Q_{i} b-T_{i-1} \chi h_{i-1}-\frac{1}{2} Q_{i-1} b,
$$

where

$$
\begin{gathered}
w_{i}=\overline{h_{i}} b \gamma, \\
\overline{h_{i}}=\frac{h_{i}+h_{i-1}}{2}, \\
\chi \in[0,1], \\
I=\frac{b^{3}}{12} .
\end{gathered}
$$

Here, $w_{i}$ is the weight of the part of stratum $i$ above the failure plane, $h_{i}$ is the equivalent height of stratum $i$ above the failure plane, $\gamma$ is the unit weight, $T_{i}$ is the normal force provided by the part of stratum $i+1$ above the failure plane, $Q_{i}$ is the tangential force provided by the part of stratum $i+1$ above the failure plane, $T_{i-1}$ is the normal force provided by the part of stratum $i-1$ above the failure plane, $Q_{i-1}$ is the tangential force provided by the part of stratum $i-1$ above the failure plane, $h_{i-1}$ is the contact height of stratum $i$ and stratum $i-1, \phi_{i}$ is the friction angle of the discontinuities, and $\chi$ is the height of the thrust line. As the derivation and verification of $\chi=0.6$ obtained in [13]

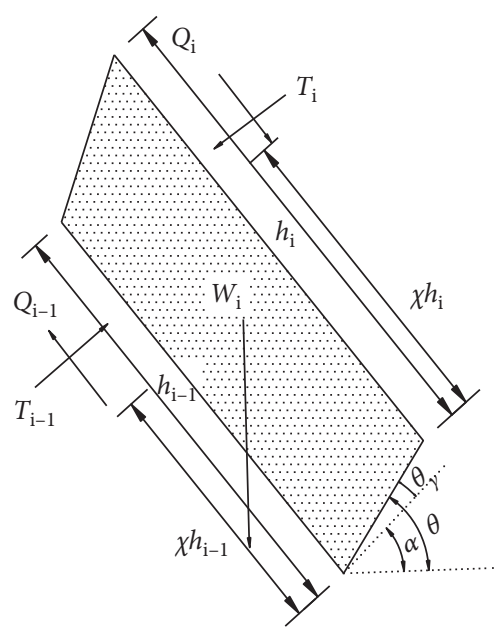

FIGURE 3: Force analysis chart of stratum $i$ for tension failure.

were extremely rigorous, the value of $\chi$ was equal to 0.6 in this manuscript.

For the calculation of the axial force exerted on column $i$, the tangential forces $\left(Q_{i}\right.$ and $\left.Q_{i-1}\right)$, neglected in previous studies, were reconsidered here, which can be written as follows:

$$
N_{i}=w_{i} \cos \alpha+Q_{i}-Q_{i-1} .
$$

For the calculation of the tangential force $\left(Q_{i}\right.$ and $\left.Q_{i-1}\right)$, the cohesion of the discontinuities $\left(c_{i}\right)$, neglected in previous studies, was reconsidered here, which can be written as follows:

$$
\begin{gathered}
Q_{i}=T_{i} \tan \phi_{i}+c_{i} h_{i}, \\
Q_{i-1}=T_{i-1} \tan \phi_{i}+c_{i} h_{i-1} .
\end{gathered}
$$

From equations (6)-(15), the value of $T_{i-1}$ can be determined as follows:

$$
T_{i-1}=\frac{T_{i}\left(\chi h_{i}-2 b \tan \phi_{i} / 3\right)+\bar{h}_{i} w_{i} \sin \alpha / 2-\left(b^{2} \sigma_{t}+b w_{i} \cos \alpha\right) / 6-\left(2 c_{i} h_{i} b / 3+c_{i} h_{i-1} b / 3\right)}{\left(\chi h_{i-1}+b \tan \phi_{i} / 3\right)} .
$$

3.2.2. Shear Failure. If shear failure occurs in stratum $i$, it should meet the Mohr-Coulomb criterion, which can be expressed as follows:

$$
\tau=\sigma \tan \phi+c
$$

Here, $\tau$ is the shear stress, $\sigma$ is the normal stress, $\phi$ is the friction angle of the rock strata, and $c$ is the cohesion.

Multiplying the bottom length $b / \cos \theta_{r}$ of the stratum on both sides of equation (18), equation (19) can be obtained as follows:

$$
\frac{\tau b}{\cos \theta_{r}}=\frac{\sigma b}{\cos \theta_{r} \tan \phi}+\frac{c b}{\cos \theta_{r}} .
$$

$$
S=N \tan \phi+\frac{c b}{\cos \theta_{r}} .
$$

Here, $S$ and $N$ represent the tangential force and the normal force of stratum $i$, respectively.

As shown in Figure 4, the tangential force and the normal force on the bottom of stratum $i$ above the failure plane can be written as follows:

$$
\begin{aligned}
S= & w_{i} \sin \theta+Q_{i} \sin \theta_{r}+P_{i} \cos \theta_{r}-Q_{i-1} \sin \theta_{r} \\
& -P_{i-1} \cos \theta_{r}, \\
N= & w_{i} \cos \theta+Q_{i} \cos \theta_{r}-P_{i} \sin \theta_{r}-Q_{i-1} \cos \theta_{r} \\
& +P_{i-1} \sin \theta_{r} .
\end{aligned}
$$

Namely, 


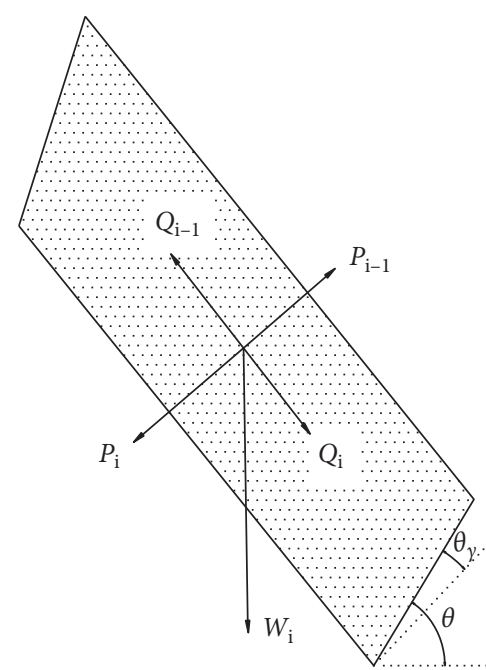

FIgURE 4: Force analysis chart of stratum $i$ for shear failure.

For the calculation of the tangential force $\left(Q_{i}\right.$ and $\left.Q_{i-1}\right)$, the cohesion of the discontinuities $\left(c_{i}\right)$, neglected in previous studies, was reconsidered in this study, which can be written as follows:

$$
\begin{gathered}
Q_{i}=P_{i} \tan \phi_{i}+c_{i} h_{i}, \\
Q_{i-1}=P_{i-1} \tan \phi_{i}+c_{i} h_{i-1} .
\end{gathered}
$$

Here, $P_{i}$ is the normal force provided by the part of stratum $i+1$ above the failure plane and $P_{i-1}$ is the normal force provided by the part of stratum $i-1$ above the failure plane.

From equations (17)-(23), the value of $P_{i-1}$ can be determined as follows:

$$
P_{i-1}=P_{i}-\frac{\cos \theta(\tan \phi-\tan \theta) w_{i}+\cos \theta_{r}\left(\tan \phi-\tan \theta_{r}\right) c_{i}\left(h_{i}-h_{i-1}\right)+c b / \cos \theta_{r}}{\cos \theta_{r}\left(1+\tan \phi_{i} \tan \theta_{r}\right)+\tan \phi \cos \theta_{r}\left(\tan \theta_{r}-\tan \phi_{i}\right)}
$$

3.2.3. Criteria for Determining Failure Modes. If $P_{i-1}>T_{i-1}$, it indicated that the thrust causing the shear failure in stratum $i$ was less than that causing bending fracture failure. In this case, we believed that stratum $i$ would be subjected to shear failure rather than bending fracture failure, and vice versa.

3.3. Amount of Failed Strata. During the calculation process, if $\max \left(P_{i-1}, T_{i-1}\right)<0$, failure would not occur for stratum $i$, and the interaction force between stratum $i$ and stratum $i-1$ would be zero. If $\max \left(P_{i-1}, T_{i-1}\right)>0$, it indicated that failure occurred for stratum $i$. Furthermore, $P_{n}=T_{n}=0$, which meant no force provided by the upper stratum was exerted on the last stratum. After the failure modes of the rock strata were determined, the residual sliding force at the toe of the slope, $\max \left(P_{0}, T_{0}\right)$, can be derived with the step-by-step method.

Then, the failure angle $\theta_{r}$ was changed constantly and the above process was repeated until the residual sliding force at the toe of the slope was less than zero for the first time. Comparing the absolute value of the residual sliding force of the last step and that of the penultimate step, the smaller value was the desired result, recorded as $F$. The failure angle corresponding to $F$ was the final failure angle. In this case, the amount of total failed strata, the amount of shear failed strata and the amount of bending fracture strata, recorded as $n m, n s$, and $n t$, respectively, can be obtained.

\section{Numerical Example}

4.1. Slate Slope in South Anhui. A slate slope in South Anhui in China [31] was taken as an engineering example. Table 1 and Figure 5 show the parameters and the geometry profile of the slope [31], respectively.

Using the proposed method developed in this paper, the final results were presented as follows.

Toppling failure occurred in the slate slope in South Anhui in China, which was consistent with field observations and the results reported in $[30,31]$. The angle between the failure plane and plane normal to discontinuities, $\theta_{r}$, was $7.9766^{\circ}$, and the amount of total failed strata was 38 . Shear failure occurred in strata 1-3, while bending tension failure occurred in the remaining failed strata. The safety factor of stability was 0.7573 , and the residual sliding force was 26.2239 MN. The failure angle obtained in [30] was $13^{\circ}$, and the amount of failed strata was 37 . Shear failure occurred in strata 1-4, and bending tension failure occurred in the remaining failed strata. The safety factor of stability calculated with Aydan and Kawamoto's method [16] was 0.9343, and the residual sliding force was 4.6781 MN (see Table 2). 
TABLE 1: Calculation parameters of rock mass of the slate slope in South Anhui in China [31].

\begin{tabular}{lcccccccc}
\hline Parameters & Values & Units & Parameters & Values & Units & Parameters & Values & Units \\
\hline$\chi$ & 0.6 & & $\eta$ & 63 & ${ }^{\circ}$ & $c$ & 0.4 & $\mathrm{MPa}$ \\
$b$ & 4 & $\mathrm{~m}$ & $\eta_{0}$ & 0 & ${ }^{\circ}$ & $c_{i}$ & 0.01 & $\mathrm{MPa}$ \\
$H$ & 100 & $\mathrm{~m}$ & $\gamma$ & 27 & $\mathrm{kN} \mathrm{m}^{-3}$ & & \\
$n$ & 40 & & $\phi_{i}$ & 18 & & & \\
$\beta$ & 55 & $\circ$ & $\phi$ & & & \\
\hline
\end{tabular}

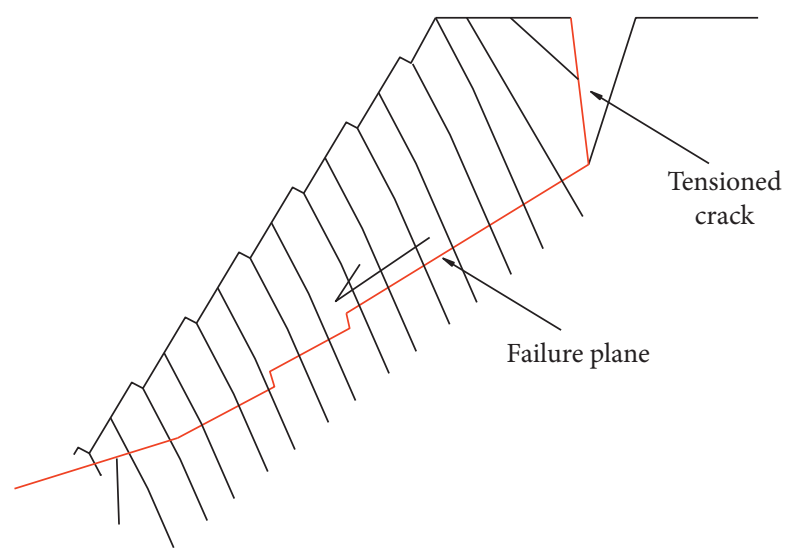

Figure 5: Schematic diagram of a slate slope in South Anhui in China [31].

TABLe 2: Result comparisons of the slate slope in South Anhui in China obtained using different methods.

\begin{tabular}{|c|c|c|c|c|c|c|}
\hline Slate slope & $\theta_{r}\left({ }^{\circ}\right)$ & ns & nt & $\mathrm{nm}$ & $F(\mathrm{MN})$ & $F_{S}$ \\
\hline Aydan and Kawamoto [16] & 0 & 0 & 40 & 40 & 4.6781 & 0.9343 \\
\hline Zheng et al. [30] & 13 & 2 & 35 & 37 & - & - \\
\hline Majdi and Amini [26] & - & - & - & - & - & 0.5430 \\
\hline Presented method & 7.9766 & 3 & 35 & 38 & 26.2239 & 0.7573 \\
\hline
\end{tabular}

Note. "-" indicates that no specific result is given.

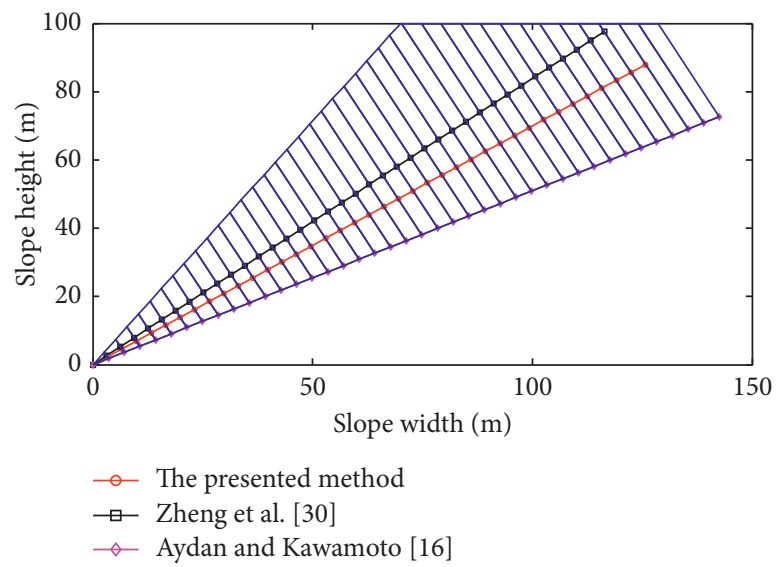

Figure 6: Slope failure planes of the slate slope in South Anhui in China obtained using different methods.

The safety factor of stability calculated with Majdi and Amini's method [26] was 0.5430 . The result comparisons of the failure planes are shown in Figure 6, and the convergence curves of the safety factor of the stability are shown in Figure 7.

According to the data presented in Section 4.1, it was found that the safety factor of the stability of the slate slope in
South Anhui in China obtained with the proposed method was smaller than that calculated with Aydan and Kawamoto's method [16]. For Aydan and Kawamoto's method [16], the plane normal to the discontinuities was considered to be the failure plane. However, the overall failure of the slate slope in South Anhui in China occurred before the damage developed to the plane normal to the 


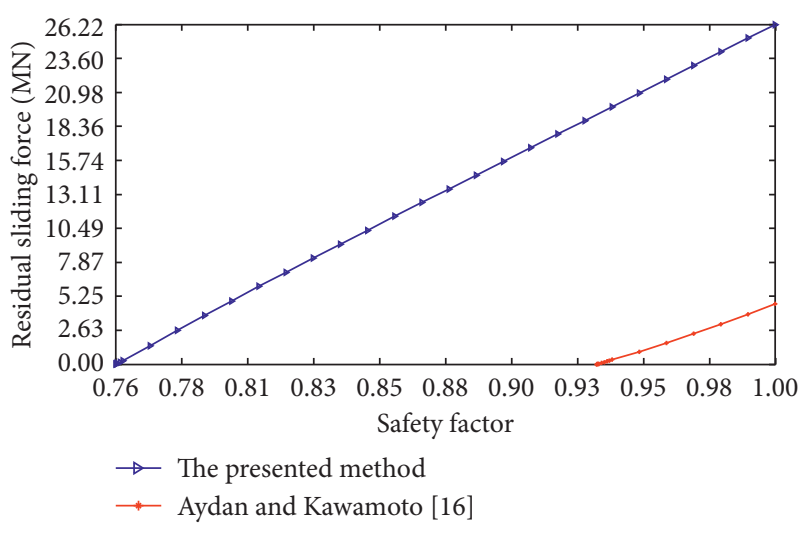

FIGURE 7: Convergence curves of the safety factor of stability of the slate slope in South Anhui in China obtained using different methods.

discontinuities. Therefore, the safety factor of stability of the slate slope in South Anhui in China calculated with Aydan and Kawamoto's method [16] was overestimated. As the effects of the cohesion of the discontinuities on the stability of the slate slope in South Anhui in China were neglected for the method developed in [30], the failure plane obtained in [30] was above the actual failure plane. Thereupon, the failure plane and the safety factor of the stability of the slate slope in South Anhui in China obtained with the presented method were credible.

4.2. Rock Slope Facing the Tehran-Chalus Road. A rock slope facing the Tehran-Chalus Road near the Amir-Kabir Dam Lake in Iran [36] was taken as another example. Table 3 and Figure 8 show the parameters and the geometry profile of the slope [36], respectively.

Using the proposed method developed in this paper, the final results were presented as follows.

The rock slope facing the Tehran-Chalus Road near the Amir-Kabir Dam Lake in Iran was stable, which was consistent with field observations and the results reported in [36]. The safety factor of stability obtained with the proposed method was 3.1666, and the residual sliding force was $-6.1078 \mathrm{MN}$. The safety factor of the stability calculated with Majdi and Amini's method [26] was 3.5990. The safety factor of the stability calculated with Aydan and Kawamoto's method [16] was 3.1082, and the residual sliding force was $-7.3278 \mathrm{MN}$. The safety factor of the stability obtained in [36] was 2.6037, and the residual sliding force was $-3.1683 \mathrm{MN}$. The result comparisons of the safety factor of the stability and the residual sliding force are shown in Table 4, and the convergence curves of the safety factor of the stability are shown in Figure 9.

According to the data presented in Section 4.2, it was found that the safety factor of the stability of the rock slope facing the Tehran-Chalus Road, obtained with the proposed method, was larger than that, obtained in [36]. In [36], the authors assumed that the joints completely cut some of the rock strata and no tensile stress existed in these rock strata, which was relatively rare in the actual slope. Therefore, the safety factor of stability of the rock slope facing the Tehran-Chalus Road obtained in [36] was underestimated. On the one hand, the effects of the cohesion of the discontinuities and the cohesion of rock strata on the stability of a slope were neglected for Aydan and Kawamoto's method [16], resulting in the underestimation of the safety factor of stability of the slope. On the other hand, the potentially shear failure of stratum 1 at the toe of the slope was neglected for Aydan and Kawamoto's method [16], resulting in the overestimation of the safety factor of stability of the slope. The safety factor of stability of the rock slope facing the TehranChalus Road obtained with Aydan and Kawamoto's method was almost equal to that obtained with the presented method due to the combined effects of the two aspects. For the Majdi and Amini's method [26], the effects of the cohesion of rock strata, the cohesion of the discontinuities, the friction angle of the rock strata, and the friction angle of the discontinuities on the stability of anaclinal layered rock slopes against flexural toppling failure were neglected, leading to a decrease of the accuracy of the safety factor of the stability. Thereupon, the safety factor of the stability of the rock slope facing the TehranChalus Road obtained with the presented method was credible.

\section{Parametric Sensibility Analyses for the Failure Angle}

The failure angle $\theta_{r}$ is an important indicator for measuring the degree of instability of anaclinal layered slopes. The position of the failure plane becomes higher as the failure angle $\theta_{r}$ increases, which indicates that it takes less time to arrive at the state of limit equilibrium, and thus, the slope is more unstable. During the computational process, many parameters may influence the failure angle $\theta_{r}$. In this section, the parametric sensibility analyses for the failure angle $\theta_{r}$ are discussed in detail. All these parameters are classified into two groups, i.e., the geometrical parameters of a slope and the mechanical parameters of rock mass. The geometrical parameters of a slope contain the height of the thrust line $\chi$, the rock thickness $b$, the slope height $H$, the dip angle of the slope $\beta$, the dip angle of the rock stratum $\eta$, and the natural slope angle $\eta_{0}$. The mechanical parameters of the rock mass contain the tensile strength $\sigma_{t}$, the cohesion of rock strata $c$, the cohesion of the discontinuities $c_{i}$, the friction angle of the rock strata $\phi$, the friction angle of the discontinuities $\phi_{i}$, and the unit weight $\gamma$. When the value of one parameter changed, the others remained the same as in Table 1.

5.1. Sensitivity Analyses of Geometrical Parameters of the Slate Slope in South Anhui. The value of one geometrical parameter of the slate slope in South Anhui was changed constantly, and the corresponding failure angles calculated through the above process are listed in Tables 5 and 6 . The failure angles changed with the changes of the geometrical parameters of the slope, and the changing laws are shown in Figure 10.

From the data in Tables 5 and 6 and Figure 10, some conclusions can be drawn as follows:

(1) The relatively sensitive parameters for the failure angle $\theta_{r}$ in the geometrical parameters of the slate slope in South Anhui were the dip angle of the slope $\beta$ and the dip angle of the rock stratum $\eta$, which was 
TABLE 3: Calculation parameters of rock mass of rock slope facing the Tehran-Chalus Road [36].

\begin{tabular}{lcccccccc}
\hline Parameters & Values & Units & Parameters & Values & Units & Parameters & Values & Units \\
\hline$\chi$ & 0.6 & & $\eta$ & 47 & ${ }^{\circ}$ & $c$ & 1.11 & $\mathrm{MPa}$ \\
$b$ & 2.31 & $\mathrm{~m}$ & $\eta_{0}$ & 29 & ${ }^{\circ}$ & $c_{i}$ & 0.1 & $\mathrm{MPa}$ \\
$H$ & 20.45 & $\mathrm{~m}$ & $\gamma$ & 26.5 & $\mathrm{kN} \mathrm{m}^{-3}$ & $\sigma_{t}$ & \\
$n$ & 16 & & $\phi_{i}$ & 30 & & & \\
$\beta$ & 85.3 & $\circ$ & $\phi$ & 45 & & & \\
\hline
\end{tabular}

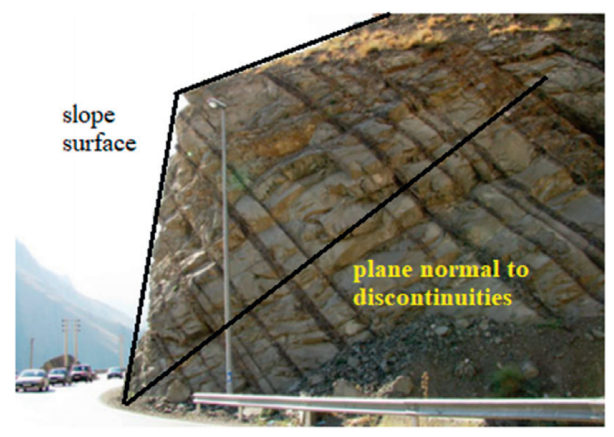

Figure 8: Rock slope facing Tehran-Chalus Road near the Amir-Kabir Dam Lake in Iran.

TABLE 4: Result comparisons of rock slope facing the Tehran-Chalus Road obtained using different methods.

\begin{tabular}{lcccc}
\hline Tehran-Chalus & Aydan and Kawamoto [16] & Majdi and Amini [26] & Amini et al. [36] & Presented method \\
\hline$F_{S}$ & 3.1082 & 3.5990 & 2.6037 & 3.1666 \\
$F(\mathrm{MN})$ & -7.3278 & - & -3.1683 & -6.1078 \\
\hline
\end{tabular}

Note. "-" indicates that no specific result is given.

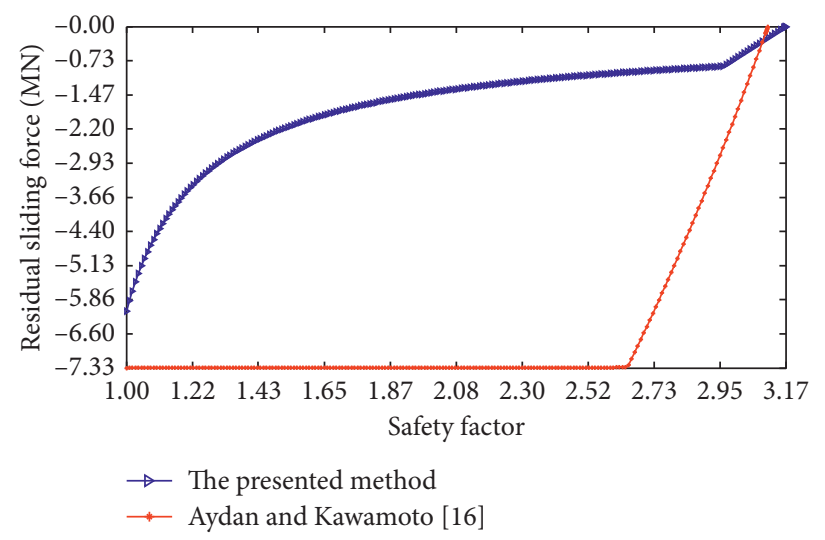

FIgURE 9: Convergence curves of the safety factor of stability of the rock slope facing the Tehran-Chalus Road obtained using different methods.

TABLE 5: Sensibility analyses of the geometrical parameters of the slate slope in South Anhui.

\begin{tabular}{ccccccrrr}
\hline Parameters & Values & $\theta_{r}\left(^{\circ}\right)$ & Parameters & Values & $\theta_{r}\left({ }^{\circ}\right)$ & Parameters & Values & $\theta_{r}\left({ }^{\circ}\right)$ \\
\hline & 0.5 & 6.4058 & & 2 & 10.3104 & & 80 & 5.2464 \\
& 0.6 & 7.9766 & & 3 & 8.7094 & & 9.7824 \\
$\chi$ & 0.7 & 9.2014 & $b(\mathrm{~m})$ & 4 & 7.9766 & $H(\mathrm{~m})$ & 100 \\
& 0.8 & 10.1287 & & 5 & 6.9476 & & 7.9766 \\
& 0.9 & 10.9281 & & 6 & 5.8870 & & 9.0023 \\
& & & & 9.7852 \\
\hline
\end{tabular}


TABLE 6: Sensibility analyses of the geometrical parameters of the slate slope in South Anhui.

\begin{tabular}{|c|c|c|c|c|c|c|c|c|}
\hline Parameters & Values & $\theta_{r}\left({ }^{\circ}\right)$ & Parameters & Values & $\theta_{r}\left({ }^{\circ}\right)$ & Parameters & Values & $\theta_{r}\left({ }^{\circ}\right)$ \\
\hline \multirow{5}{*}{$\eta_{0}\left({ }^{\circ}\right)$} & 0 & 7.9766 & \multirow{5}{*}{$\beta\left(^{\circ}\right)$} & 45 & - & \multirow{5}{*}{$\eta\left(^{\circ}\right)$} & 55 & - \\
\hline & 5 & 8.1398 & & 50 & 2.5753 & & 60 & 4.9877 \\
\hline & 10 & 8.3440 & & 55 & 7.9766 & & 63 & 7.9766 \\
\hline & 15 & 8.5585 & & 60 & 13.6030 & & 65 & 9.9294 \\
\hline & 20 & 8.7808 & & 65 & 19.4932 & & 70 & 14.5796 \\
\hline
\end{tabular}

Note. "-" indicates that the slope is stable.

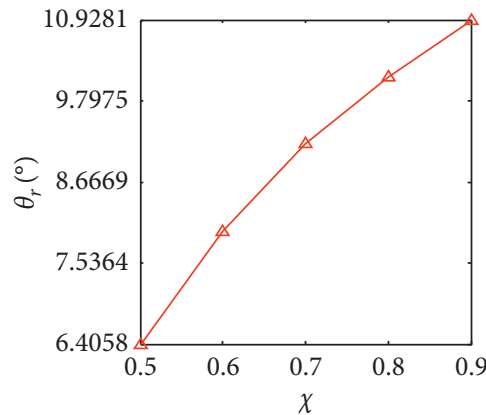

(a)

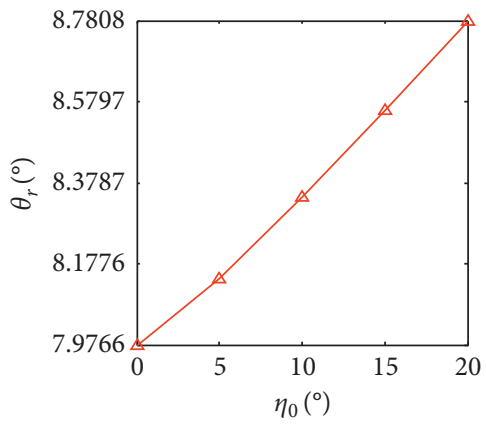

(d)

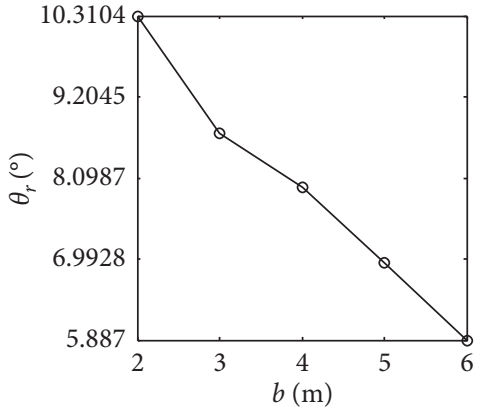

(b)

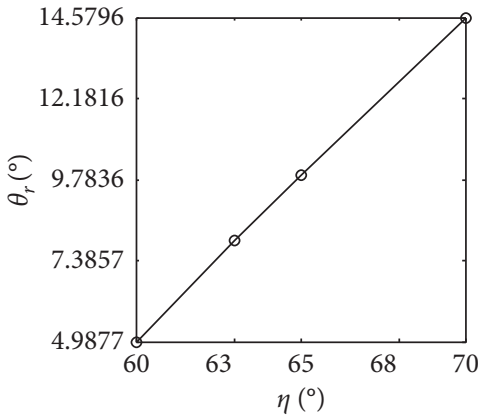

(e)

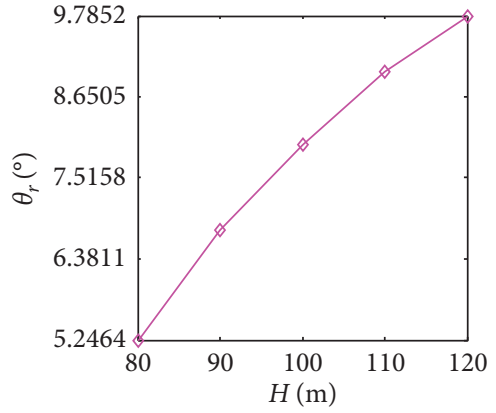

(c)

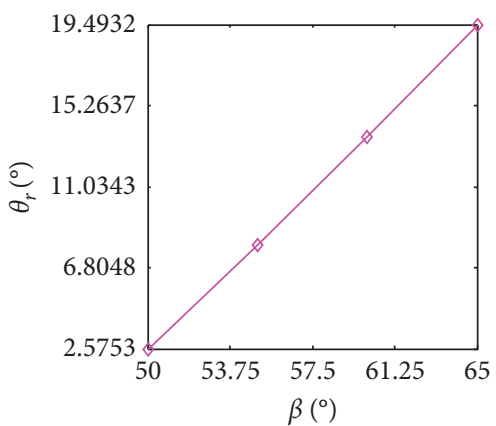

(f)

FIgURE 10: Sensitivity analyses of geometrical parameters of the slate slope in South Anhui.

consistent with the result obtained in [30]. The effect degree of these two sensitive parameters for the failure angle $\theta_{r}$ was $\beta>\eta$. For the anaclinal layered rock slopes, their failure was mainly associated with the upper parts of the rock strata above the plane normal to the discontinuities. When the dip angle of the slope or the dip angle of the rock stratum became larger, the possible failure zones of the slope increased, and thus, the slope was more unstable.

(2) When $\beta=45^{\circ}$ or $\eta=55^{\circ}$, the slope was stable. This result further verified Goodman and Bray's viewpoint [5] that only if inequality (25) was satisfied, the overall failure of an anaclinal layered rock slope would occur.

$$
\beta-\left(90^{\circ}-\eta\right)>\phi_{i}
$$

(3) The thickness $b$ is an important indicator for measuring the ability to resist the bending deformation [37]. However, the thickness $b$ was not the most sensitive parameter for the failure angle $\theta_{r}$ in the geometrical parameters of the slate slope in South Anhui according to the results obtained in this study, i.e., it was not the controlling factor for the overall failure of the slate slope, which was consistent with the opinion of [30].

(4) When the geometrical parameters of the slope, except for the rock thickness $b$, became larger, the failure angle $\theta_{r}$ increased, which indicated that the slope was more unstable.

5.2. Sensitivity Analyses of Mechanical Parameters of Rock Mass of the Slate Slope in South Anhui. The value of one mechanical parameter of the rock mass of the slate slope in South Anhui was changed constantly, and the corresponding failure angles calculated through the above process are listed in Tables 7 and 8 . The failure angles changed with the changes of the mechanical parameter of the rock mass, and the changing laws are shown in Figure 11.

From the data in Tables 7 and 8 and Figure 11, some conclusions can be drawn as follows: 
TABLE 7: Sensibility analyses of the mechanical parameters of the rock mass of the slate slope in South Anhui.

\begin{tabular}{|c|c|c|c|c|c|c|c|c|}
\hline Parameters & Values & $\theta_{r}\left({ }^{\circ}\right)$ & Parameters & Values & $\theta_{r}\left({ }^{\circ}\right)$ & Parameters & Values & $\theta_{r}\left({ }^{\circ}\right)$ \\
\hline \multirow{5}{*}{$c_{i}(\mathrm{MPa})$} & 0 & 8.1830 & \multirow{5}{*}{$\sigma_{t}(\mathrm{MPa})$} & 1.0 & 9.1689 & \multirow{5}{*}{$c(\mathrm{MPa})$} & 0.2 & 10.3858 \\
\hline & 0.01 & 7.9766 & & 1.2 & 8.6778 & & 0.3 & 8.9295 \\
\hline & 0.02 & 7.7669 & & 1.5 & 7.9766 & & 0.4 & 7.9766 \\
\hline & 0.03 & 7.5544 & & 1.8 & 7.3296 & & 0.5 & 7.2976 \\
\hline & 0.04 & 7.3382 & & 2.0 & 6.9286 & & 0.6 & 6.7945 \\
\hline
\end{tabular}

TABLE 8: Sensibility analyses of the mechanical parameters of the rock mass of the slate slope in South Anhui.

\begin{tabular}{|c|c|c|c|c|c|c|c|c|}
\hline Parameters & Values & $\theta_{r}\left({ }^{\circ}\right)$ & Parameters & Values & $\theta_{r}\left({ }^{\circ}\right)$ & Parameters & Values & $\theta_{r}\left({ }^{\circ}\right)$ \\
\hline \multirow{5}{*}{$\phi\left({ }^{\circ}\right)$} & 30 & 8.5268 & \multirow{5}{*}{$\phi_{i}\left({ }^{\circ}\right)$} & 10 & 13.1107 & \multirow{5}{*}{$\gamma\left(\mathrm{kN} \cdot \mathrm{m}^{-3}\right)$} & 23 & 6.9042 \\
\hline & 35 & 8.3731 & & 15 & 10.0839 & & 25 & 7.4735 \\
\hline & 40 & 8.1866 & & 18 & 7.9766 & & 27 & 7.9766 \\
\hline & 45 & 7.9766 & & 20 & 6.4187 & & 29 & 8.4535 \\
\hline & 50 & 7.7720 & & 25 & 1.5086 & & 31 & 8.9040 \\
\hline
\end{tabular}

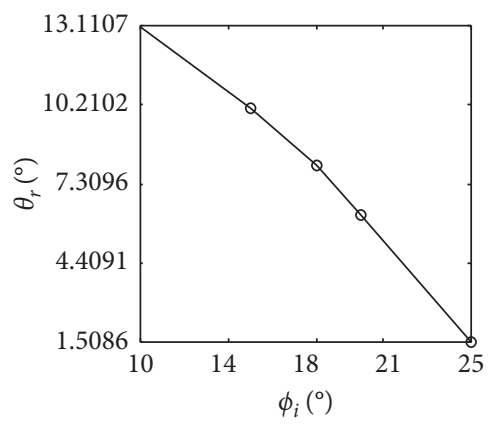

(a)

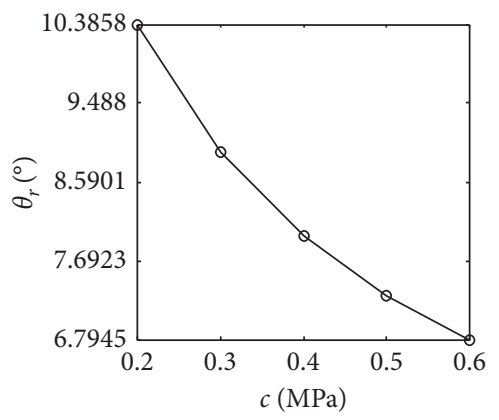

(d)

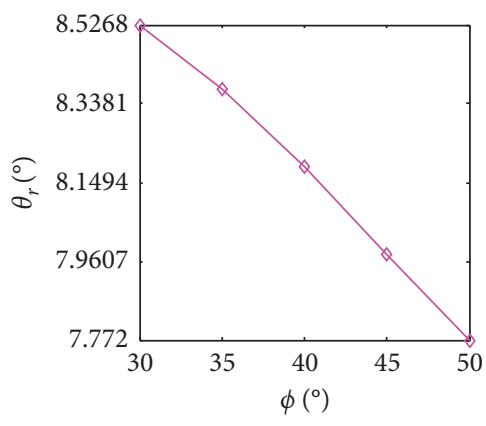

(b)

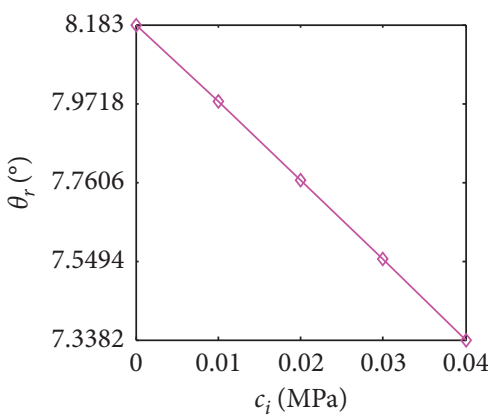

(e)

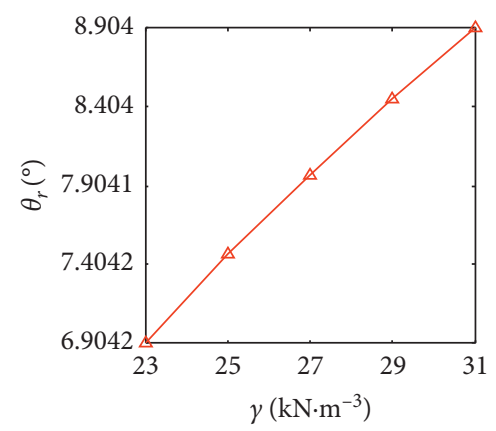

(c)

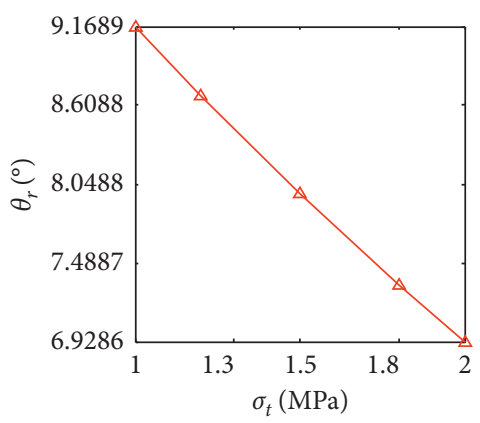

(f)

FIGURE 11: Sensitivity analyses of the mechanical parameters of the rock mass of the slate slope in South Anhui.

(1) The most sensitive parameter for the failure angle $\theta_{r}$ in the mechanical parameters of the rock mass of the slate slope in South Anhui was the friction angle of the discontinuities, $\phi_{i}$, which verified Goodman and Bray's viewpoint [5] that the intense interlayer movement was the precondition for the toppling failure.

(2) The tensile strength $\sigma_{t}$ is an important indicator for measuring the ability to resist the bending tension failure [38]. The cohesion $c$ and the friction angle of the rock strata $\phi$ are the major parameters of shear failure [39]. However, these three parameters were proven not to be the most sensitive parameters for the failure angle $\theta_{r}$ according to the results obtained in this study, i.e., they were not the controlling factors for the overall failure of the slate slope, which was consistent with the opinion of [40].

(3) When the mechanical parameters of the rock mass, except for the unit weight $\gamma$, became larger, the failure angle $\theta_{r}$ became smaller, which indicated that the slope was more stable.

\section{Discussion}

Based on the above analyses, it was clear that the dip angle of the slope, $\beta$, the dip angle of the rock stratum, $\eta$, and the 
friction angles of the discontinuities, $\phi_{i}$, were the most sensitive parameters for the failure angle $\theta_{r}$, which indicated that these three parameters were the controlling factors for the overall failure of the slate slope in South Anhui in China. The effect degree of these three controlling factors for the overall failure of the slate slope was $\beta>\eta>\phi_{i}$.

As we all know, the failure of a slope depends on the stress distribution and the strength of the rock mass. The stress distribution of a slope is mainly affected by the geometrical morphology of the slope, and the strength of the rock mass is mainly controlled by the characteristics of the rock mass discontinuities. For an anaclinal layered slope, the dip angle of the slope, $\beta$, and the dip angle of the stratum, $\eta$, are the two main factors of the geometrical morphology. The friction angle of the discontinuities, $\phi_{i}$, is a significant parameter for measuring the ability to resist movement between layers. Hence, these three parameters are the controlling factors for the overall failure of the slate slope in South Anhui in China.

\section{Conclusions}

As the shear failure occurred near the slope toe, the effects of the cohesion of the discontinuities on the stability of anaclinal layered rock slopes against flexural toppling failure and the contribution of tangential force to cross-section axial force were neglected in previous studies, and none of the experts had developed a rigorously theoretical method for determining the angle between the failure plane and the plane normal to the discontinuities for a slope, an optimization of the analytical method for determining the flexural toppling failure plane based on the limit equilibrium theory was developed and the corresponding formulations were derived in this study. After that, the effectiveness of the proposed method was verified by taking a slate slope in South Anhui in China and a rock slope facing the TehranChalus Road near the Amir-Kabir Dam Lake in Iran, and the sensitive analyses of the parameters used in the calculation process of the slope failure angle were performed as well. Eventually, some conclusions can be drawn as follows.

The proposed method, developed based on the limit equilibrium theory, is feasible to determine the flexural toppling failure plane, which was verified by the case history study.

If the geometrical parameters of a slope, except for the rock thickness, increase, the slope will be more unstable. If the mechanical parameters of the rock mass, except for the unit weight, increase, the slope will be more stable. The dip angle of the slope, the dip angle of the rock stratum, and the friction angle of the discontinuities are the controlling factors for the overall failure of the slate slope in South Anhui in China.

It should be noted that the results obtained in this study only applied to the ultimate failure of anaclinal layered slopes and can be used for preliminary evaluation of the stability.

\section{Data Availability}

All data generated or analyzed during this study are included in this article.

\section{Conflicts of Interest}

The authors declare that there are no conflicts of interest regarding the publication of this paper.

\section{Acknowledgments}

This study has been financially supported by the Doctoral Scientific Research Fund of the Anyang Institute of Technology (Grant no. BSJ2018009). The authors would like to thank LetPub (http://www.letpub.com) for providing linguistic assistance during the preparation of this manuscript.

\section{References}

[1] X. Z. Chen and Y. F. Cui, "The formation of the Wulipo landslide and the resulting debris flow in Dujiangyan city, China," Journal of Mountain Science, vol. 14, no. 6, pp. 1100-1112, 2017.

[2] M. H. De Freitas and R. J. Watters, "Some field examples of toppling failure," International Journal of Rock Mechanics and Mining Sciences \& Geomechanics Abstracts, vol. 11, no. 3, pp. 495-513, 1974.

[3] Z. Li, J. Wang, L. Li, L. Wang, and R. Y. Liang, "A case study integrating numerical simulation and GB-InSAR monitoring to analyze flexural toppling of an anti-dip slope in Fushun open pit," Engineering Geology, vol. 197, pp. 20-32, 2015.

[4] S. Wang, "On the mechanism and process of slope deformation in an open pit mine," Rock Mechanics Felsmechanik Mecanique Des Roches, vol. 13, no. 3, pp. 145-156, 1981.

[5] R. E. Goodman and J. W. Bray, "Toppling of rock slopes," in Proceedings of the Specialty Conference on Rock Engineering for Foundations and Slopes ASCE, pp. 201-243, Boulder Geotechnical Engineering Division of ASCE, Boulder, CO, USA, August 1976.

[6] O. Aydan, Y. Shimizu, and Y. Ichikawa, "The effective failure modes and stability of slopes in rock mass with two discontinuity sets," Rock Mechanics and Rock Engineering, vol. 22, no. 3, pp. 163-188, 1989.

[7] A. Bobet, "Analytical solutions for toppling failure," International Journal of Rock Mechanics and Mining Sciences, vol. 36, no. 7, pp. 971-980, 1999.

[8] G. Y. Liu, J. J. Li, and F. Kang, "Failure mechanisms of toppling rock slopes using a three-dimensional discontinuous deformation analysis method," Rock Mechanics and Rock Engineering, vol. 52, no. 10, pp. 3825-3848, 2019.

[9] C. H. Liu, M. B. Jaksa, and A. G. Meyers, "Improved analytical solution for toppling stability analysis of rock slopes," International Journal of Rock Mechanics and Mining Sciences, vol. 45, no. 8, pp. 1361-1372, 2008.

[10] C. H. Liu, M. B. Jaksa, and A. G. Meyers, "A transfer coefficient method for rock slope toppling," Canadian Geotechnical Journal, vol. 46, no. 1, pp. 1-9, 2009.

[11] G. X. Zhang, Y. Zhao, and X. C. Peng, "Simulation of toppling failure of rock slope by numerical manifold method," International Journal of Computational Methods, vol. 7, no. 1, pp. 167-189, 2010.

[12] J. H. Zhang, Z. Y. Chen, and X. G. Wang, "Centrifuge modeling of rock slopes susceptible to block toppling," Rock Mechanics and Rock Engineering, vol. 40, no. 4, pp. 363-382, 2007.

[13] D. P. Adhikary, A. V. Dyskin, R. J. Jewell, and D. P. Stewart, "A study of the mechanism of flexural toppling failure of rock 
slopes," Rock Mechanics and Rock Engineering, vol. 30, no. 2, pp. 75-93, 1997.

[14] M. Amini, H. Sarfaraz, and K. Esmaeili, "Stability analysis of slopes with a potential of slide-head-toppling failure," International Journal of Rock Mechanics and Mining Sciences, vol. 112, pp. 108-121, 2018.

[15] O. Aydan and M. Amini, "An experimental study on rock slopes against flexural toppling failure under dynamic loading and some theoretical considerations for its stability assessment," Journal of the College of Marine Science and Technology Tokai University, vol. 7, no. 2, pp. 25-40, 2009.

[16] O. Aydan and T. Kawamoto, "The stability of slopes and underground openings against flexural toppling and their stabilisation," Rock Mechanics and Rock Engineering, vol. 25, no. 3, pp. 143-165, 1992.

[17] C. M. Lo and M. C. Weng, "Identification of deformation and failure characteristics in cataclinal slopes using physical modeling," Landslides, vol. 14, no. 2, pp. 499-515, 2017.

[18] H. Sarfaraz, M. H. Khosravi, and M. Amini, "Numerical analysis of slide-head-toppling failure," Journal of Mining and Environment, vol. 10, no. 4, pp. 1001-1011, 2019.

[19] L. F. Xie, E. C. Yan, J. H. Wang, G. D. Lu, and G. M. Yu, "Study on evolutionary characteristics of toppling deformation of reverse-dip layered rock slope based on surface displacement monitoring data," Environmental Earth Sciences, vol. 77, no. 4, p. 156, 2018.

[20] Z. L. Zhang, T. Wang, S. Wu, and H. M. Tang, "Rock toppling failure mode influenced by local response to earthquakes," Bulletin of Engineering Geology and the Environment, vol. 75, no. 4, pp. 1361-1375, 2016.

[21] G. C. Zhang, F. Wang, H. Zhang, H. M. Tang, X. H. Li, and Y. Zhong, "New stability calculation method for rock slopes subject to flexural toppling failure," International Journal of Rock Mechanics and Mining Sciences, vol. 106, pp. 319-328, 2018.

[22] Y. Zheng, C. X. Chen, T. T. Liu, H. N. Zhang, K. Z. Xia, and F. Liu, "Study on the mechanisms of flexural toppling failure in anti-inclined rock slopes using numerical and limit equilibrium models," Engineering Geology, vol. 237, pp. 116128, 2018.

[23] D. P. Adhikary, A. V. Dyskin, and R. J. Jewell, "Modeling of flexural toppling failures of rock slopes," in Proceedings of the Eighth International Congress on Rock Mechanics: Proceedings, vol. 1, pp. 379-382, CRC Press/Balkema, Rotterdam, Netherlands, January 1995.

[24] D. P. Adhikary and A. V. Dyskin, "Modelling of progressive and instantaneous failures of foliated rock slopes," Rock Mechanics and Rock Engineering, vol. 40, no. 4, pp. 349-362, 2007.

[25] M. Amini, A. Majdi, and Ö. Aydan, "Stability analysis and the stabilisation of flexural toppling failure," Rock Mechanics and Rock Engineering, vol. 42, no. 5, pp. 751-782, 2009.

[26] A. Majdi and M. Amini, "Analysis of geo-structural defects in flexural toppling failure," International Journal of Rock Mechanics and Mining Sciences, vol. 48, no. 2, pp. 175-186, 2011.

[27] X. P. Zhou and H. Cheng, "Analysis of stability of three-dimensional slopes using the rigorous limit equilibrium method," Engineering Geology, vol. 160, no. 12, pp. 21-33, 2013.

[28] X. P. Zhou and H. Cheng, "Stability analysis of three-dimensional seismic landslides using the rigorous limit equilibrium method," Engineering Geology, vol. 174, no. 8, pp. 87-102, 2014.

[29] X. P. Zhou and H. Cheng, "The long-term stability analysis of $3 \mathrm{D}$ creeping slopes using the displacement-based rigorous limit equilibrium method," Engineering Geology, vol. 195, pp. 292-300, 2015.

[30] Y. Zheng, C. X. Chen, X. M. Liu et al., "Investigation on calculation method of layered counter-tilt slope for flexural toppling failure," Chinese Journal of Rock Mechanics and Engineering, vol. 34, no. S2, pp. 4252-4261, 2015.

[31] H. J. Liu, Research on the Toppling Deformation Mechanism of Counter-Tilt Slate Slope in the Mountainous Zone of Southern Anhui, Chengdu University of Technology, Chengdu, China, 2012.

[32] J. S. Cai, E. C. Yan, Z. Q. Wang, J. G. Yang, and R. X. Tang, "Study of cantilever beam limit equilibrium model of anti-dip layered rock slopes," Rock and Soil Mechanics, vol. 35, no. S1, pp. 15-28, 2014.

[33] R. E. Goodman and D. S. Kieffer, "Behavior of rock in slopes," Journal of Geotechnical and Geoenvironmental Engineering, vol. 126, no. 8, pp. 675-684, 2000.

[34] G. Z. Sun and W. B. Zhang, "A commonly-sighted rock mass structure-slab-rent structure and its mechanical model," Chinese Journal of Geology, vol. 3, no. 3, pp. 275-282, 1985.

[35] S. Timoshenko, Strength of Materials. Advanced Theory and Problems, Van Nostrand Reinhold, NewYork, NY, USA, 3rd edition, 1974.

[36] M. Amini, A. Majdi, and M. A. Veshadi, "Stability analysis of rock slopes against block-flexure toppling failure," Rock Mechanics and Rock Engineering, vol. 45, no. 4, pp. 519-532, 2012.

[37] Z. M. Lu, C. X. Chen, B. C. Zuo, and C. Q. Huang, "Experimentation research on factors influencing stability of antidip layered slope," Rock and Soil Mechanics, vol. 27, no. 4, pp. 629-624, 2006.

[38] A. K. Alzo'ubi, C. D. Martin, and D. M. Cruden, "Influence of tensile strength on toppling failure in centrifuge tests," International Journal of Rock Mechanics and Mining Sciences, vol. 47, no. 6, pp. 974-982, 2010.

[39] B. C. Zuo, C. X. Chen, X. W. Liu, and Q. Shen, "Modeling experiment study on failure mechanism of counter-tilt rock slope," Chinese Journal of Rock Mechanics \& Engineering, vol. 24, no. 19, pp. 3505-3511, 2005.

[40] J. Muralha, "Parameter variability in the toppling stability of rock blocks," in Proceedings of the 10th Conference of the International Society for Rock Mechanic, Technology Road Map for Rock Mechanics, pp. 849-854, The South African Institute of Mining and Metallurgy, Johannesburg, South Africa, September 2003. 